\title{
A Study on Prevalence, Type and Severity of Anemia in Helicobacter Pylori Infection with Respect to RBC Parameters in a Tertiary Care Hospital
}

\author{
Dr. Nazran Akbar Hussain ${ }^{1}$ and Dr. Nisha TG $^{2 *}$
}

\author{
${ }^{1}$ Postgraduate, Department of Pathology, Yenepoya Medical College, Deralakatte, Mangalore, India \\ ${ }^{2}$ Associate Professor, Department of Pathology, MES Medical College, Perinthalmanna, Malappuram District, Kerala, India
}

DOI: $\underline{10.36348 / \text { sjpm.2021.v06i03.003 }}$

| Received: 27.02.2021 | Accepted: 15.03.2021 | Published: 18.03.2021

*Corresponding author: Dr. Nisha TG

\section{Abstract}

Introduction: Helicobacter pylori (H.pylori) has been reported as an etiological agent in many gastric disorders and contribute to Iron deficiency anemia with an increasing prevalance in developing countries. The effect of H.pylori infection on haematological diseases is not well understood. Objective: To detect the prevalence, type and severity of anemia in H.pylori positive cases and to correlate it with RBC parameters. Methods: A retrospective study was done on biopsy proven cases of H.pylori over a period of one year. RBC parameters including Hemoglobin, RBC count, PCV, $\mathrm{MCV}, \mathrm{MCH}, \mathrm{MCHC}$ and Peripheral Smear report were retrieved from the hospital software system. Patients with $\mathrm{Hb}$ $<13 \mathrm{gm} / \mathrm{dl}$ (males) and $<12 \mathrm{gm} / \mathrm{dl}$ (females) were considered as anemic, graded as mild, moderate and severe, based on WHO guidelines. Data was entered into excel sheet and statistical analysis was done. Results: The study included 100 H.Pylori positive cases, of which 71 were male and 29 female. Prevalence of anemia was $74 \% .23$ cases were microcytic hychochromic (MCHC), 37 normocytic normochromic (NCNC), 9 macrocytic and 5 dimorphic anemia. 10\%, 46\%, 18\% and $26 \%$ had mild, moderate, severe anemia and no anemia respectively. A significant association was noted between type and severity of anemia. In MCHC anemia, all the RBC indices had significant correlation ( $\mathrm{p}<0.05)$; others correlated with PCV and RBC counts. Conclusions: This study indicates that H.pylori infection is related to moderate degree of anemia, predominantly of NCNC type, with significant association of RBC indices to MCHC anemia. All patients diagnosed as having H.pylori infection, would hence benefit from being investigated for underlying anemia.

Keywords: H.pylori, Prevalence, Anemia, Severity, RBC parameters.

Copyright (C) 2021 The Author(s): This is an open-access article distributed under the terms of the Creative Commons Attribution 4.0 International License (CC BY-NC 4.0) which permits unrestricted use, distribution, and reproduction in any medium for non-commercial use provided the original author and source are credited.

\section{INTRODUCTION}

Helicobacter pylori (H.pylori) are spiralshaped or curved gram-negative, urease-producing organisms present in gastric biopsy specimens of most of the individuals with gastric ulcers or chronic gastritis $[1,2]$. H.pylori infection prevalence was reported to span from $8.7 \%$ to $85.5 \%$, which increased with age and varies widely by race, ethnicity, geographic area and socio- economic status [3,4]. It is one of the most common infections in the world, with an approximate $50 \%$ of the world's population being carriers of the bacterium [5].

H.pylori has been reported as an etiological agent in chronic gastritis, gastric and duodenal ulcers, and gastric malignancies and contributes to Iron deficiency anemia (IDA) with an increasing prevalance in developing countries [6]. The sequel of H.pylori infection on haematological system diseases is not well known [7].
Anemia is pathophysiologically diverse and multifactorial and is characterized by decreased quantity of red blood cells, often accompanied by reduced hemoglobin level and altered red cell morphology [8]. The most common form of anemia worldwide is Iron deficiency anemia. Globally this public health problem has affected both developing and developed countries, with prime consequences for human health as well as social and economic development [5]. However, relationship between H.pylori infection and anemia has been explored by earlier epidemiological studies in different settings. Studies have found that, especially in female subjects with H.pylori infection had higher prevalence of anemia [9]. Anemia is often diagnosed as the first clinical manifestation or the only sign of an underlying $\mathrm{H}$. pylori infection; hence it is important to know the cause of anemia to eradicate the problem [6]. The present study was undertaken to detect the prevalence of anemia in $\mathrm{H}$. pylori infected cases and to find the type 
and severity of anemia in H.pylori positive cases in correlation with RBC parameters.

\section{MATERIALS AND METHODS}

A retrospective study was conducted from July 2019 to June 2020 on histopathologically proven positive cases of H.Pylori, in Yenepoya Medical College Hospital, Mangalore, after approval from the Institutional Ethical committee. All the histopathologically proven cases of H.pylori infection that were above the age of 18 years were included in the study and patients less than 18 years of age and patients who were pregnant were excluded from the study.

Based on the above mentioned criteria, 100 cases of histopathologically proven positive cases of H.Pylori were taken from the archives of Pathology department, the relevant demographic details and laboratory data were retrieved from the hospital software system. The hematological RBC parameters like Hemoglobin value, RBC count, PCV, MCV, MCH, $\mathrm{MCHC}$ and Peripheral Smear report were recorded.

Patients with $\mathrm{Hb}<13 \mathrm{gm} / \mathrm{dl}$ and $<12 \mathrm{gm} / \mathrm{dl}$ was considered as anemia for males and females respectively. Anemia was graded into mild, moderate and severe anemia based on WHO guidelines, that is for non-pregnant women (15 years of age and above) 11$11.9 \mathrm{~g} / \mathrm{dl}, 8-10.9 \mathrm{~g} / \mathrm{dl}$ and $<8 \mathrm{~g} / \mathrm{dl}$ was considered as mild, moderate and severe anemia respectively, $\geq 12$ $\mathrm{g} / \mathrm{dl}$ was considered as no anemia whereas, in men (15 years of age and above) 11-12.9 g/dl, 8-10.9 g/dl and < $8 \mathrm{~g} / \mathrm{dl}$ was considered as mild, moderate and severe anemia respectively, $\geq 13 \mathrm{~g} / \mathrm{dl}$ was considered as no anemia [10].

\section{STATISTICAL ANALYSIS}

The data were entered into Microsoft excel sheet and analyzed using the software SPSS 23 version. Frequencies and percentage of all the variables were computed. Pearson's correlation was used to know the association between the severities of anemia in H.pylori positive cases with the RBC parameters. P-value $<0.05$ was considered significant.

\section{RESULTS}

The study included $100 \mathrm{H}$. pylori positive cases, of which 71 were males and 29 females. In this study, youngest patient was 20 years of age and oldest was 76years. Majority $(n=28)$ of the patient were in the $5^{\text {th }}$ decade. Subjects had a mean age (SD) of 47.75 (13.73) years.

\section{Distribution of cases}

Prevalence of anemia in this study was $74 \%$. Out of the total number of cases, the study included predominantly Normocytic Normochromic anemia (NCNC) cases, $37 \%$ with mean haemoglobin level (SD) of $9.77 \pm 1.69 \mathrm{~g} / \mathrm{dl}$ followed by $26 \%$ of cases having no anemia with mean haemoglobin (SD) of $14.11 \pm 1.27$ $\mathrm{g} / \mathrm{dl}$, they were showing a Normocytic Normochromic blood picture in the peripheral smear, which correlated with the RBC indices provided by the RBC analyser. In this study only $23 \%$ of cases showed Microcytic Hypochromic anemia (MCHC) with mean haemoglobin level $(\mathrm{SD})$ of $7.83 \pm 1.8 \mathrm{~g} / \mathrm{dl} .9 \%$ and $5 \%$ of the cases had Macrocytic anemia and Dimorphic anemia respectively with their mean haemoglobin (SD) value being $8.21 \pm 2.05 \mathrm{~g} / \mathrm{dl}$ and $8 \pm 2.05 \mathrm{~g} / \mathrm{dl}$ respectively [Fig$1]$.

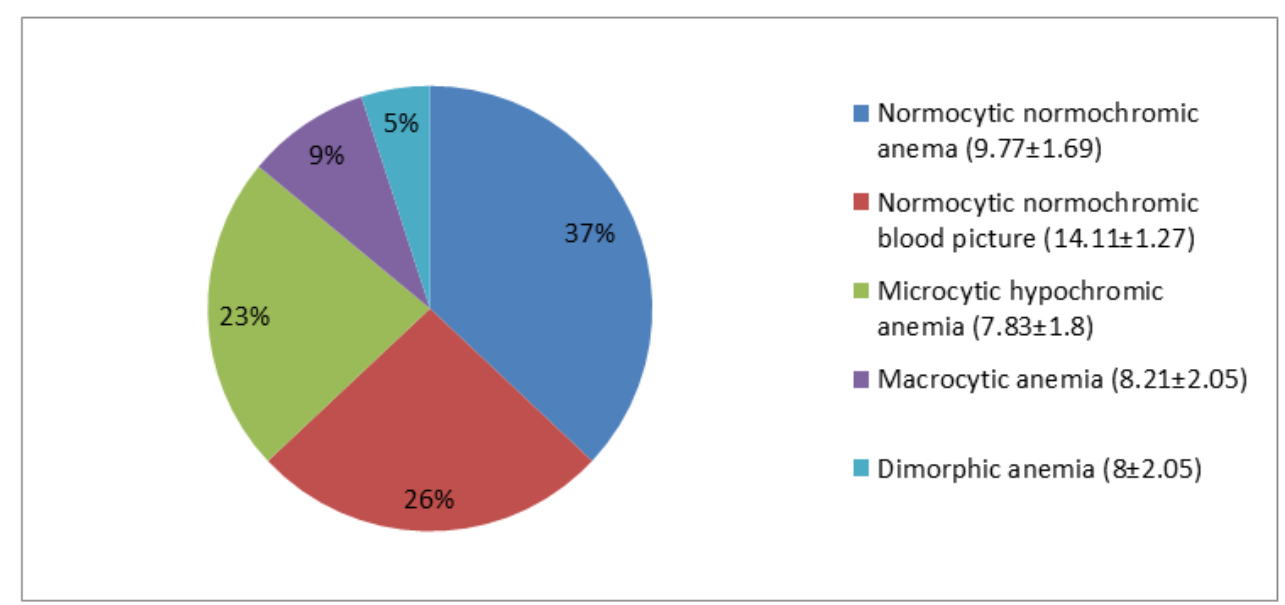

Fig-1: Distribution of cases with mean hemoglobin level and standard deviation

Out of the total number of cases of anemia $(\mathrm{n}=74, \quad 100 \%), \quad 13.5 \%(\mathrm{n}=10), \quad 62.2 \%(\mathrm{n}=46)$ and $24.3 \%(n=18)$ were having mild, moderate and severe amount of anemia respectively and $31.1 \%(\mathrm{n}=23)$, $50 \%(n=37), 12.2 \%(n=9)$ and $6.8 \%(n=5)$ were having MCHC anemia, NCNC anemia, Macrocytic anemia and
Dimorphic anemia respectively. Out of the total number of MCHC anemia cases, $17.6 \%(n=13)$ were having moderate amount of MCHC anemia and $13.5 \%(n=10)$ were having severe form of MCHC anemia. Of the $50 \%$ $(n=37)$ cases of NCNC anemia, $13.5 \%(n=10), 32.4 \%$ $(n=24)$ and $4.1 \%(n=3)$ cases had mild, moderate and 
severe form of NCNC anemia respectively. Out of $12.2 \%(n=9)$ cases of Macrocytic anemia 8.1\% ( $n=6)$ were having moderate amount and $4.1 \%(n=3)$ were having severe Macrocytic anemia. 4.1\% ( $n=3)$ and $2.7 \%(\mathrm{n}=2)$ cases of Dimorphic anemia had moderate and severe amount of anemia respectively [Table-1].

Table-1: Association between type and severity of anemia

\begin{tabular}{|l|l|l|l|l|}
\hline \multirow{2}{*}{ PERIPHERAL } & \multicolumn{2}{l|}{ HEMOGLOBIN } & \multirow{2}{*}{ TOTAL } \\
\cline { 2 - 4 } & MILD & MODERATE & SEVERE & TOTA \\
\hline MCHC ANEMIA & 0 & 13 & 10 & 23 \\
& $0.0 \%$ & $17.6 \%$ & $13.5 \%$ & $31.1 \%$ \\
\hline NCNC ANEMIA & 10 & 24 & 3 & 37 \\
& $13.5 \%$ & $32.4 \%$ & $4.1 \%$ & $50 \%$ \\
\hline MACROCYTIC & 0 & 6 & 3 & 9 \\
ANEMIA & $0.0 \%$ & $8.1 \%$ & $4.1 \%$ & $12.2 \%$ \\
\hline DIMORPHIC & 0 & 3 & 2 & 5 \\
ANEMIA & $0.0 \%$ & $4.1 \%$ & $2.7 \%$ & $6.8 \%$ \\
\hline TOTAL & 10 & 46 & 18 & 74 \\
& $13.5 \%$ & $62.2 \%$ & $24.3 \%$ & $100 \%$ \\
\hline
\end{tabular}

\section{Correlation of Anemia and $\mathrm{RBC}$ indices}

In $\mathrm{MCHC}$ anemia all the $\mathrm{RBC}$ indices including $\mathrm{RBC}$ count, $\mathrm{MCV}, \mathrm{MCH}, \mathrm{MCHC}$ and $\mathrm{PCV}$ were correlating, and $\mathrm{p}$-value was $<0.01$, whereas, in
NCNC anemia and Macrocytic anemia only RBC count and PCV were correlating, where p-value was $<0.05$. In Dimorphic anemia only PCV was correlating with type of anemia, where p-value was $<0.05$ [Table-2].

Table-2: Association between type of anemia and RBC indices

\begin{tabular}{|c|c|c|c|c|c|c|c|}
\hline $\begin{array}{l}\text { PERIPHERAL } \\
\text { SMEAR }\end{array}$ & & & $\mathbf{R B C}$ & MCV & МCH & МСНC & PCV \\
\hline \multirow[t]{3}{*}{ MCHC anemia } & \multirow[t]{3}{*}{$\mathrm{Hb}$} & $\begin{array}{l}\text { Pearson } \\
\text { Correlation }\end{array}$ & $.673^{* *}$ & $.550^{* * *}$ & $.631^{* * *}$ & $.551^{* * *}$ & $.871^{* * *}$ \\
\hline & & Sig. (2-tailed) & .000 & .007 & .001 & .006 & .000 \\
\hline & & $\mathrm{N}$ & 23 & 23 & 23 & 23 & 23 \\
\hline \multirow[t]{3}{*}{ NCNC anemia } & \multirow[t]{3}{*}{$\mathrm{Hb}$} & $\begin{array}{l}\text { Pearson } \\
\text { Correlation }\end{array}$ & $.920^{* * *}$ & -.046 & .060 & .169 & $.967^{* * *}$ \\
\hline & & Sig. (2-tailed) & .000 & .786 & .723 & .318 & .000 \\
\hline & & $\mathrm{N}$ & 37 & 37 & 37 & 37 & 37 \\
\hline \multirow[t]{3}{*}{ Macrocytic anemia } & \multirow[t]{3}{*}{$\mathrm{Hb}$} & $\begin{array}{l}\text { Pearson } \\
\text { Correlation }\end{array}$ & $.934^{* *}$ & -.528 & -.515 & -.277 & $.981^{* * *}$ \\
\hline & & Sig. (2-tailed) & .000 & .144 & .156 & .471 & .000 \\
\hline & & $\mathrm{N}$ & 9 & 9 & 9 & 9 & 9 \\
\hline \multirow[t]{3}{*}{ Dimorphic anemia } & \multirow[t]{3}{*}{$\mathrm{Hb}$} & $\begin{array}{l}\text { Pearson } \\
\text { Correlation }\end{array}$ & $.879^{*}$ & .022 & .010 & -.010 & $.958^{*}$ \\
\hline & & Sig. (2-tailed) & .050 & .972 & .987 & .987 & .010 \\
\hline & & $\mathrm{N}$ & 5 & 5 & 5 & 5 & 5 \\
\hline
\end{tabular}

\section{DISCUSSION}

Anemia is regarded as a complication of $\mathrm{H}$. pylori infection [11]. In this study, we found that the subjects with $\mathrm{H}$. pylori infection had higher prevalence of anemia (74\%), than those quoted by other studies conducted on the Chinese adult population where their prevalence rate was $5.5 \%, 9.7 \%$ and $16.3 \%[12,13]$.

We found that prevelance of anemia was seen predominantly in females $(75 \%)$ when compared to males $(73.2 \%)$ which was in accordance with other studies [9]. Shih, H. Y. et al. observed a lower level of haemoglobin in the positive $\mathrm{H}$. pylori infection group for male subjects. Although, this association was not found in all subjects [14].
One more study indicated that haemoglobin levels had statistical significance among past infection, long-term infection, recent infection and no infection subjects. That study inferred that a lower level of haemoglobin was related to the presence of older age and gastric atrophy rather than the presence of $\mathrm{H}$. pylori infection itself [15]. A meta-analysis of randomized control trials of $\mathrm{H}$. pylori eradication has indicated that eradication can increase haemoglobin levels [16].

We observed a lower haemoglobin level in female subjects when compared to other studies done in Beijing and Taiwan, where they had lower hemoglobin in male subjects $[9,14]$. In our study, subjects with $H$. pylori infection had predominantly NCNC anemia 
which was in accordance with study conducted by $\mathrm{Xu}-$ mei et al. and also in their study mild anemia was predominant while in our study moderate anemia was predominant [9].

Study done by Mei-Yan $\mathrm{Xu}$ et al. revealed significant differences in $\mathrm{RBC}, \mathrm{MCV}, \mathrm{MCH}$, and MCHC between H. pylori (-) and H. pylori (+) groups, but these changes are not likely to be biologically significant [9]. In our study, we did not have H. pylori negative group but our analysis revealed significant correlation between MCHC anemia and RBC parameters $(\mathrm{p}<0.05)$.

A range of evidence from clinical and epidemiological studies holds up a relationship between H. pylori infection and anemia. Although, reports from different countries and areas are not accordant regarding this relationship between $\mathrm{H}$. pylori infection and anemia and the underlying mechanisms remain uncertain [9]. There are several mechanisms that might explain the relationship between $\mathrm{H}$. pylori infection and anemia [9]. The most predictable mechanism is gastrointestinal blood loss due to $\mathrm{H}$. pylori-induced gastritis or duodenitis. An additional possibility is that the H. pylori bacterial sequestration of free iron affects iron transporter molecules, bywhich inhibits free iron absorption. Additionally, H. pylori gastric colonization requires uninterrupted supplementation of nutrients necessary for bacterial growth and can utilise the host's own iron stores [9].

Study by A. E. Kurekci et al. results support the proposal that $\mathrm{H}$. pylori infection is associated with IDA, and complete recovery of anemia can be achieved with the treatment of $H$. pylori infection $[6,16]$. A study done by Saler $\mathrm{T}$ et al. showed that men with normal gastrointestinal endoscopy results had no association of iron deficiency anemia with $\mathrm{H}$. pylori infection. In general population Iron deficiency anemia is a common health problem. In a similar manner, $\mathrm{H}$. pylori are a common gastrointestinal tract infection that affects a majority of the population. Guidelines on iron deficiency anemia have confirmed the etiological role of H.pylori, but the relationship remains controversial [5].

Huang et al. [17] reported that H. pylori eradication therapy combined with iron administration is more efficient than iron administration alone for the treatment of iron deficiency anemia and also it's well understood from their study that all patients in their study had gastrointestinal problems because they were given bismuth or proton pump inhibitors based triple therapy. In such cases iron deficiency anemia is a expected condition due to impaired mucosa. Since in our study we have not taken endoscopic findings into account, we do not know the gastrointestinal mucosa status.
A study done on large sample size of 882 patients in Taiwan by Hsiang-Yao et al. showed no significant association between anemia and chronic $\mathrm{H}$. pylori infections, but they did not exclude most of the concomitant conditions. Furthermore in their study, gastrointestinal system endoscopy was not performed for all of the subjects [14]. Qu et al. performed a metaanalysis of observational studies and randomized controlled trials, and they inferred that iron deficiency anemia could not specifically be associated to $\mathrm{H}$. pylori infections [18].

\section{CONCLUSION}

This study indicates that $\mathrm{H}$. pylori infection is related to moderate degree of anemia, predominantly of NCNC type, with significant association of RBC indices to MCHC anemia. A larger sample size may be needed to show precise association between H.pylori infection and anemia. All patients diagnosed as having H. pylori infection, would hence benefit from being investigated for underlying anemia.

\section{REFERENCES}

1. Kumar, V., Abbas, A., \& Aster, J. (2020). Robbins $\&$ cotran pathologic basis of disease (10th ed., pp. 767-768). ELSEVIER.

2. Bini, E. J. (2001). Helicobacter pylori and iron deficiency anemia: guilty as charged?. The American journal of medicine, 111(6), 495-497.

3. Carabotti, M., D'Ercole, C., Iossa, A., Corazziari, E., Silecchia, G., \& Severi, C. (2014). Helicobacter pylori infection in obesity and its clinical outcome after bariatric surgery. World Journal of Gastroenterology: WJG, 20(3), 647.

4. Xia, W., Zhang, X., Wang, J., Sun, C., \& Wu, L. (2012). Survey of anaemia and Helicobacter pylori infection in adolescent girls in Suihua, China and enhancement of iron intervention effects by $\mathrm{H}$. pylori eradication. British Journal of Nutrition, 108(2), 357-362.

5. Saler, T., Keşkek, Ş. Ö., Kırk, S., Ahbab, S., \& Ortoğlu, G. (2014). H. pylori may not be associated with iron deficiency anemia in patients with normal gastrointestinal tract endoscopy results. Advances in hematology, 2014.

6. Emin Kurekci, A., Avni Atay, A., Umit Sarici, S., Yesilkaya, E., Senses, Z., Okutan, V., \& Ozcan, O. (2005). Is there a relationship between childhood Helicobacter pylori infection and iron deficiency anemia?. Journal of tropical pediatrics, 51(3), 166169.

7. Taye, B., Enquselassie, F., Tsegaye, A., Amberbir, A., Medhin, G., Fogarty, A, \& Davey, G. (2015). Effect of early and current Helicobacter pylori infection on the risk of anaemia in 6.5-year-old Ethiopian children. BMC infectious diseases, 15(1), 270.

8. Kassebaum, N. J., Jasrasaria, R., Naghavi, M., Wulf, S. K., Johns, N., Lozano, R., \& Flaxman, S. 
R. (2014). A systematic analysis of global anemia burden from 1990 to 2010. Blood, 123(5), 615-624.

9. Xu, M. Y., Cao, B., Yuan, B. S., Yin, J., Liu, L., \& Lu, Q. B. (2017). Association of anaemia with Helicobacter pylori infection: a retrospective study. Scientific reports, 7(1), 1-7.

10. World Health Organization. (2011). Haemoglobin concentrations for the diagnosis of anaemia and assessment of severity (No. WHO/NMH/NHD/ MNM/11.1). World Health Organization.

11. Cardamone, M., Alex, G., Harari, M. D., Moss, W. P., \& Oliver, M. R. (2008). Severe iron deficiency anaemia in adolescents: Consider Helicobacter pylori infection. Journal of paediatrics and child health, 44(11), 647-650.

12. Wang, K., \& Wang, R. (2003). Meta-analysis on the epidemiology of Helicobacter pylori infection in China.

13. Hu, Y., Chen, J., Li, M., Li, W., Yang, Y., Yang, L., \& Piao, J. (2016). Study on the anemia status of Chinese urban residents in 2010-2012. Zhonghua yu fang yi xue za zhi [Chinese journal of preventive medicine], 50(3), 213.

14. Shih, H. Y., Kuo, F. C., Wang, S. S., Liu, Y. C., Wu, M. C., Chang, Y. P., \& Chen, Y. L. (2013). Helicobacter pylori infection and anemia in
Taiwanese adults. Gastroenterology Research and Practice, 2013.

15. Lee, S. Y., Yang, J. H., Hong, S. N., Kim, J. H., Sung, I. K., Park, H. S., \& Shim, C. S. (2012). Su1655 Low Hemoglobin Levels are related to the Presence of Gastric Atrophy rather Than the Presence of H. pylori Infection Itself: A Study of 2,398 Asymptomatic Adults. Gastroenterology, 142(5), S-474.

16. Wenzhen, Y., Yumin, L., Kehu, Y., Bin, M., Quanlin, G., Donghai, W., \& Lijuan, Y. (2010). Iron deficiency anemia in Helicobacter pylori infection: meta-analysis of randomized controlled trials. Scandinavian journal of gastroenterology, 45(6), 665-676.

17. Huang, X., Qu, X., Yan, W., Huang, Y., Cai, M., $\mathrm{Hu}, \mathrm{B} .$, \& Lu, L. (2010). Iron deficiency anaemia can be improved after eradication of Helicobacter pylori. Postgraduate medical journal, 86(1015), 272-278.

18. Qu, X. H., Huang, X. L., Xiong, P., Zhu, C. Y., Huang, Y. L., Lu, L. G., \& Lin, H. (2010). Does Helicobacter pylori infection play a role in iron deficiency anemia? A meta-analysis. World journal of gastroenterology: WJG, 16(7), 886. 